Review Paper

\title{
Nanotechnology implications for high performance lubricants
}

\author{
Deepika $^{1}$
}

Received: 28 January 2020 / Accepted: 15 May 2020 / Published online: 26 May 2020

(c) Springer Nature Switzerland AG 2020

\begin{abstract}
Nanomaterials have emerged as potential environment friendly lubricant additives to upgrade the conventional lubricants such as automotive oils, industrial oils, grease, and metal working fluids. The applications of nanoparticle additives are based on the principles of solid lubrication and are mostly used as anti-wear, anti-friction and extreme pressure additives. Their various advantages include small enough size, thermal stability, variety of particle chemistries and a high reaction rate with the surface without induction period. These advantages translate into longer equipment operation, increased fuel efficiency and extended maintenance intervals. Thus, the current article designates on the benefits/ advantages of nano materials as lubricant additives and their applications in various automotive/engine/industrial oils. Further, it covers on (a) the major types of industrial oils and their key properties/functions and (b) different nanomaterials that are currently being explored as lubricant additives, their thermal stability and technical challenges.
\end{abstract}

Keywords Nanomaterials · Lubricants · Additives · Tribology

\section{Introduction}

Lubrication is vitally important for both domestic and industrial processes. During the past decades, great efforts have been made to develop environment friendly lubricants to improve the operating efficiency, prolong the service life of machinery, and decrease long term costs. A lubricant performs a number of critical functions that include lubrication, cooling, cleaning, suspending, and protecting metal surfaces against corrosive damage. Lubricant comprises a base fluid and an additive package the primary function of the base fluid is to lubricate and act as a carrier of additives. Additives are chemical compounds added to lubricating oils to impart specific properties to the finished oils. Performance of a lubricant is enhanced in multiple ways by adding a combination of additives such as antifriction, anti-wear, extreme pressure, anti-oxidant, anti-corrosion and detergent [1-5]. Such additives include organo-molybdenum compounds and organo-zinc phosphate compounds. While these additives are particularly useful as friction and wear reducers/modifiers, they may have one or more of the following disadvantages: poor oil solubility; copper and/or lead corrosion; color darkening of the finished lubricant; and increased levels of Sulphur and/or phosphorus in the finished lubricant. Therefore, a need exists for lubricant additives and compositions that can improve the overall performance of the lubricant while being more environment-friendly and compatible with pollution control devices used for automotive and diesel engines [6]. Ever increasing severity in operating conditions and advances in equipment technology coupled with rising lubrication requirements as well as the increasingly stringent regulatory requirements across a variety of markets are the key reasons for the exploration of new kind of additives and optimization of their concentrations.

However, technological trends and literature analysis show that significant progress has been achieved with the application of nanomaterials based on carbon, metals, metal oxides, metal sulphides, metal borates and metal carbonates, in improving the properties and performance

Deepika, m2deepikasingh@gmail.com | Institute for Frontier Materials, Deakin University, Waurn Ponds, VIC 3216, Australia. 
of lubricants [1]. Nanoparticle additives are based on the principles of solid lubrication and are mostly used as antiwear, anti-friction and extreme pressure additives [7-10].

Major technical challenge of achieving stability of nano lubricant additives in base oil has been accomplished using various approaches such as surface modification, surfactant-assisted dispersion and in situ synthesis in base oil, which has provided much needed momentum for realizing the commercial potential of these materials.

Tungsten disulphide $\left(\mathrm{WS}_{2}\right)$ nanomaterial is the world's first commercial lubricant additive that uses multi-layered fullerene shaped nanospheres and nanotubes from inorganic compounds to reduce high load level friction and wear [2]. There are seven nano-enabled lubricants $\left(\mathrm{WS}_{2}\right.$, $\mathrm{MoS}_{2}$, diamond, boron, copper, zirconium and platinum ceramic and nano-emulsions) that have been commercialized so far but only the first five have found major applications. Figure 1 shows the major commercialized nano-lube additives and their manufacturers.

The benefits of nano-based lubricants additive can be summarized in three categories: operational, economic and environmental gains. Reduction in friction will improve performance of equipment and machinery as well as reduce wear i.e. the frequency of maintenance can be reduced [5]. The economic benefits are that with good lubricity less fuel is consumed, and the life of the machinery extended. Down times are less frequent, cutting losses from lack of productivity. Environmental benefits include improved fuel efficiency and a reduction in emissions and particulate matter, experimentally it was seen that nanoparticles, added to various oils/lubricants exhibit good tribological properties $[3,11,12]$. In addition, nano-lubes are commonly made from nontoxic materials that are environmentally friendly. Figure 2 depicts a comparison of the commercial nano-lubricant additives.
From Fig. 2 it is obvious that $\mathrm{WS}_{2}, \mathrm{MoS}_{2}$, diamond and boron nanomaterials have shown excellent metal bonding capacity. Additionally, nano-diamond helps to polish the internal parts of the engine [3]. The nano-lube additives market is fragmented and characterized by many competitors. The competition among the participants in these industries is characterized by the need to provide customers with cost effective, technologically-capable products that meet or exceed industry specifications.

\section{Benefits of using nanomaterials as lubricant additives}

Nanomaterials can be considered as potential environment benign lubricant additives. They present several advantages compared to organic molecules currently used as lubricant additives. Nanomaterial additives can help in increasing lubricity, counteracting friction, reducing wear, and improving load bearing ability thereby saving energy, increasing the efficiency of dynamic transmission, dampening vibrations, and reducing noise. The major advantages of nanoparticles that have been utilized as lubricant additives to upgrade the conventional lubricants are due to the small scale effects, insensitivity to temperature, and good tribological characteristics [3].

Nano particulate additives may function in different ways. The mechanisms by which oils having nano-additives reduce friction and wear under boundary lubrication are the colloidal effect, rolling effect, small-size effect, protective film effect and third body effect [4]. Soft nanomaterials act as a cohesive third body that can exist between two surfaces to reduce wear and reduce friction, which radically deforms under load and accommodates surface velocity differences mostly by adhering to surfaces and

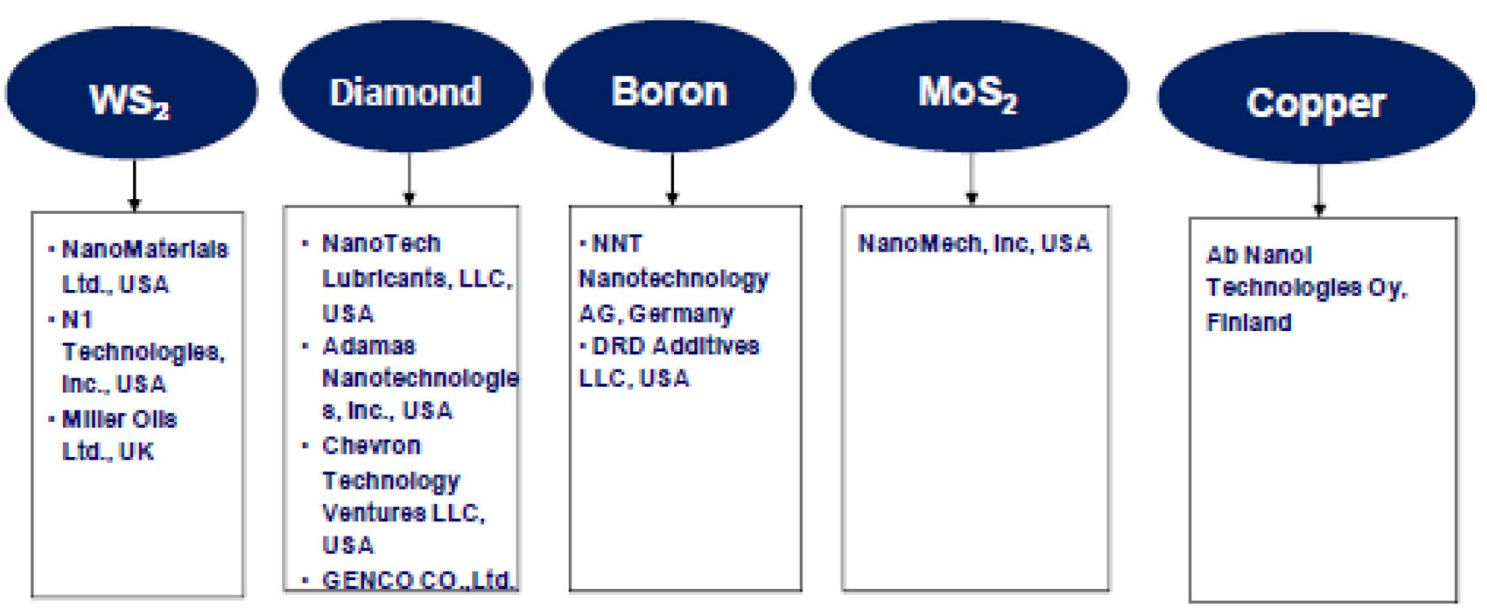

Fig. 1 Major commercial nano-lubricant additive 


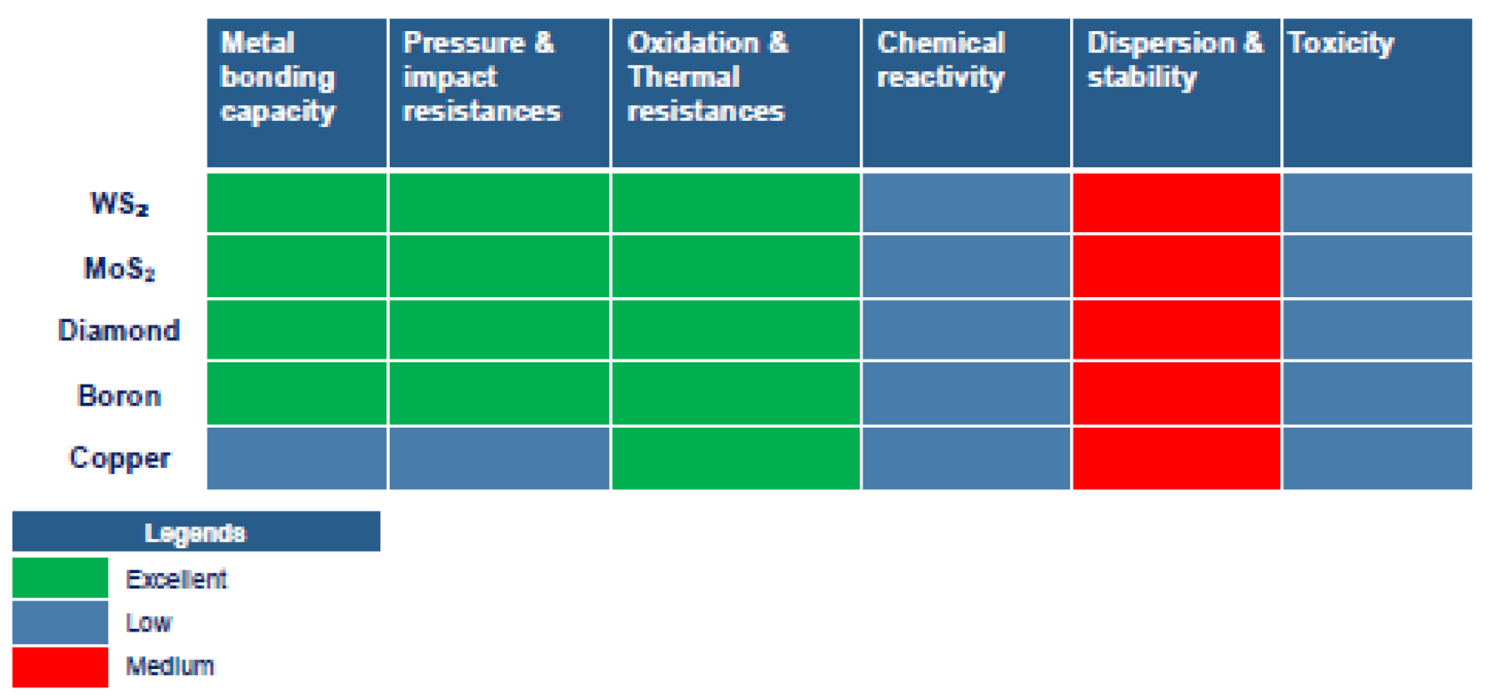

Fig. 2 Characteristics comparison of commercialized nano-lubricant additives

shearing in the bulk medium. Granular nanomaterials are cohesion less hard particles that adequately maintain their spherical geometry under load and accommodate surface velocity differences through sliding and rolling at low shear rates.

\subsection{Applications}

Potential applications of nano-enabled lubricant additives in.

\subsubsection{Automotive oils}

Engine oil lubricants make up nearly one-half of the lubricant market and therefore attract a lot of interest. Currently lubricant formulators are looking to achieve improved fuel economy through lower viscosity engine oils and by using new and more effective friction modifiers [13-16]. The key functions of automotive engine oil are as follows

- Provides stable oil film between sliding surfaces.

- Provides reliable engine operation in a wide temperature range.

- Rust/corrosion protection of the engine parts.

- Cleaning the sludge from engine parts.

- Prevention of foaming.

\subsubsection{Rail road engine oils}

Railroad applications use primarily diesel engines. Significant developments are taking place in the field of diesel engine lubrication. The operating environment of diesel locomotive engines imposes high mechanical and thermal stresses on various engine components including the lubricant [17-19]. Increasing demand for greater horsepower per cylinder and stringent emission regulations regarding $\mathrm{NO}_{x}$ and particulate matter have posed new challenges for developing high performance lubricants for railroad applications. The key properties and functions of railroad engine oils are as follows:

- Good detergency and dispersancy properties to reduce piston deposits.

- Good oxidation and thermal stability to minimize oil degradation and sludge formation.

- Good anti-wear properties.

- High alkalinity to neutralize acids formed during normal engine operation.

\subsubsection{Marine engine oils}

With the rapid development of newer and larger models of marine diesel engine to new and large models, the consumption of fuel oils has considerably increased. There is a need to concurrently improve the quality of lubricating oils to aid the in the process of design and management of marine engines [20-23]. Various key properties and functions of marine engine oils are given below:

- Rust/corrosion protection of the engine parts.

- High alkalinity.

- Load-carrying ability.

- Effective water separation properties.

- Efficient demulsibility characteristics. 


\subsubsection{Industrial oils}

Industrial lubricants are used in a wide variety of industrial machines such as hydraulic systems, turbines, compressors, bearings, open and closed gears, machine tool slideway, pneumatic tools and industrial transmissions
[24-26]. Depending on the requirement and applications, the lubricant formulations vary in composition [3]. Major types of industrial oils and their key properties and functions are listed below in Table 1.

The following Fig. 3 shows the nanotechnology implications in the development of new performance enhanced lubricant formulations.

Table 1 Major types of industrial oils and their key properties and functions

\begin{tabular}{|c|c|}
\hline Category & Properties \\
\hline Hydraulic oil & $\begin{array}{l}\text { Low temperature sensitivity of viscosity } \\
\text { Thermal and chemical stability } \\
\text { Low compressibility } \\
\text { Hydrolytic stability (ability to retain properties in the high humidity environment) } \\
\text { Water emulsifying ability } \\
\text { Filterability } \\
\text { Rust and oxidation protection properties } \\
\text { Low flash point (the lowest temperature, at which the oil vapors are ignitable) } \\
\text { Protect against cavitations } \\
\text { Low foaming } \\
\text { Compatibility with sealant materials }\end{array}$ \\
\hline Gear oil & $\begin{array}{l}\text { Must protect against spitting, spalling, scoring and scuffing caused by the large shear loads } \\
\text { placed on the oil by the gear set } \\
\text { Protect against copper corrosion } \\
\text { Limited slip oils must enable the cone or clutch work properly when distributing power to } \\
\text { the drive wheels }\end{array}$ \\
\hline Cutting fluid & $\begin{array}{l}\text { High thermal conductivity for cooling } \\
\text { Good lubricating qualities } \\
\text { High flash point (to reduce fire hazard) } \\
\text { Must not produce gummy or solid precipitate at ordinary working temperatures } \\
\text { Oxidation stability } \\
\text { Must not promote corrosion or discoloration of work material } \\
\text { Ideal viscosity that will permit easy flow from the work and dripping from chips }\end{array}$ \\
\hline Compressor oil & $\begin{array}{l}\text { Excellent rust and corrosion protection } \\
\text { High oxidation stability to maintain its viscosity and provide long service life } \\
\text { Non-foaming } \\
\text { Demulsibility properties to shed water } \\
\text { Filterability without the worry of lubricant additive depletion }\end{array}$ \\
\hline Transformer oil & $\begin{array}{l}\text { Prevention of electrical discharges between the transformer coils, corona and arc (insulating) } \\
\text { Removal of heat generated by the transformer (cooling) }\end{array}$ \\
\hline
\end{tabular}

Fig. 3 Nanotechnology implications for high performance lubricants

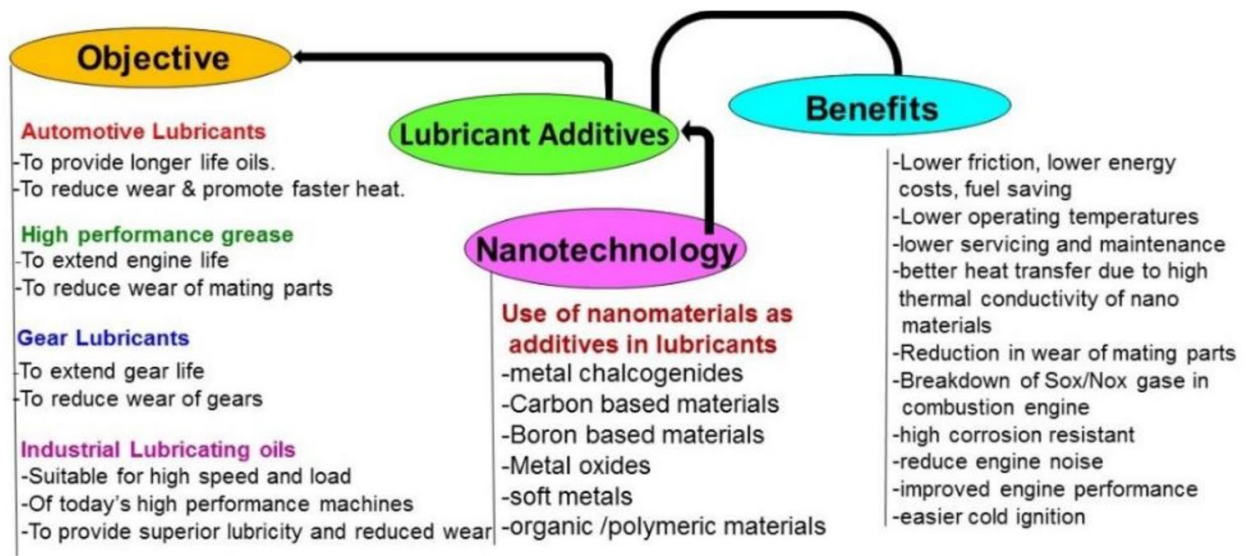




\section{Nanomaterials used as lubricant additives}

Several types of nanomaterials, predominantly of inorganic type, have been used as additives in various types of lubricating oils [11]. Nanoparticle additives are based on the principles of solid lubrication and have been regarded as excellent candidates to replace traditional extreme pressure (EP) and anti-wear (AW) additives. The reduction of friction and wear are dependent on the characteristics of nanoparticles such as size, shape and concentration [5]. Various mechanisms by which the nanomaterials added to a lubricating oil act are as follows:

- Nanoparticles are more likely to interact with the surfaces of the friction pairs to form a surface protective film.

- Small spherical nanoparticles are more likely to roll between the surfaces and change the sliding friction for a mixing of sliding and rolling friction.

- Compressive stress concentrations associated with high contact pressure can be reduced by many nanoparticles, which bear the compressive force.

- Nanoparticles are deposited on the surface forming a physical tribofilm that compensates for the loss of mass.

Broadly, nanomaterials used as additives can be classified into metal chalcogenides, soft metals, carbon based materials, boron based materials, single/mixed oxides, and organic/polymer materials [4]. Table 2 shows the properties, advantages and disadvantages of different classes of properties, advantages and disadvantages of different classes of materials.

Various nanomaterials belonging to different class of materials are being used as lubricant additives [27-32]. Table 3 shows the different nanomaterials under each category that are currently being explored as lubricant additives.

It is evident from the literature that most of the work has been focused on nano-copper, nano-diamond, carbon nanotubes, silica nanomaterials and molybdenum disulfide.

\section{Nanomaterials and property correlations}

The main role of nano lubricant additives is to improve the tribological properties of lubricants. They are mostly used as anti-wear, anti-friction and extreme pressure additives. Nano additives reduce friction and wear between the mating surfaces and increase thermal conductivity of lubricant thereby reducing the heat buildup, resulting in improved fuel efficiency of automotive engines $[11,12]$. Stringent regulatory demands to limit the sulfur content and particulate emissions from diesel fuels have resulted in decreasing the sulfur and phosphorus containing additives in lubricating oils. This adversely affects the lubricating capacity of diesel oil and accelerates wear in engine components [7]. Nano additives have been used to enhance the lubricity of engine oils. Under boundary lubrication conditions, when the boundary films fail or get broken, solid nano additives can improve the tribological properties of sliding contact surfaces, carry the load and act as back-up lubricating films.

\subsection{Dosage of nanomaterials}

Nanomaterials can improve the tribological properties of the base oil; however, the extent of improvement depends on various factors including the type of material, size and loading of nano-materials. In general, the tribological properties are significantly improved by using small and well-distributed nanomaterials. Presence of larger particles increases the abrasiveness and prevents the formation of protective film on the lubricating surface, thus results in inferior tribological properties [12]. An optimal concentration of nanomaterials is also required to achieve the desired improvement in tribological properties. This is due to the fact that at very low concentration, formation of a continuous protective film is inhibited and at concentrations higher than the optimal value, crowding of nanoparticles result in increased abrasiveness, both of which result in poorer tribological properties [8]. For a given type of nanomaterial, smaller particles are required in low concentration to improve the performance of the lubricating oil because the number of particles is higher at a given concentration. The required dosage also depends on the type of nanomaterial and application. The optimum sizes and dosages of various nanomaterials used as lubricant additives.

\subsection{Stability profile of nano lubricant additives}

The key to the nano lubricant additive technology is the stable suspension of nano sized particles in oils. Due to the high surface area and surface energy, nanoparticles tend to aggregate, which eventually leads to precipitation. Aggregation of nanoparticles is determined by the sum of attractive and repulsive forces between these particles. If the attractive forces prevail over repulsive ones, then the particles aggregate into clusters [10]. Therefore, in order to improve the stability of nanomaterial dispersion, repulsive 
Table 2 Different class of nanomaterials used as lubricant additives, their properties, advantages and disadvantages

\begin{tabular}{|c|c|c|}
\hline Material class & Advantages & Disadvantages \\
\hline Metal chalcogenides & $\begin{array}{l}\text { Work best in vacuum or dry running conditions } \\
\text { Highly anisotropic physical properties } \\
\text { Weak binding between layers leads to the useful } \\
\text { lubrication properties } \\
\text { Well-suited for cryogenic applications } \\
\text { Lowest-friction materials known in dry and vacuum } \\
\text { environments }\end{array}$ & $\begin{array}{l}\text { Degrade rather quickly in moist and oxidizing environ- } \\
\text { ments } \\
\text { Tend to oxidize at elevated temperatures }\end{array}$ \\
\hline Soft metals & $\begin{array}{l}\text { Long wear life or durability } \\
\text { Low shear strength and high plasticity, recrystal- } \\
\text { lization, oxidation resistance, good transfer-film } \\
\text { forming tendency }\end{array}$ & $\begin{array}{l}\text { Most of them react with sulfur and chlorine (if present } \\
\text { in the operating environment) and may undergo } \\
\text { rapid corrosive wear }\end{array}$ \\
\hline Carbon-based materials & $\begin{array}{l}\text { Lamellar structure } \\
\text { High wear resistance } \\
\text { Provides good lubricity } \\
\text { Available in abundance at low cost } \\
\text { Heat resistant, radiation hard, durable and provide } \\
\text { Low CoF }(0.01-0.10) \text { with a number of tribocouples }\end{array}$ & $\begin{array}{l}\text { In dry air, inert atmosphere, or vacuum, lubricity } \\
\text { degrades rapidly, the friction coefficient increases } \\
\text { and wear increases rapidly } \\
\text { Less load-carrying capacity }\end{array}$ \\
\hline Boron-based materials & $\begin{array}{l}\text { High refractory and lubricity qualities at elevated } \\
\text { temperatures } \\
\text { High thermal and chemical stability and does not } \\
\text { appreciably oxidize up to about } 1000^{\circ} \mathrm{C} \\
\text { Chemically inert } \\
\text { Typical friction coefficients in air are } 0.2-0.3 \text { up to } \\
\text { about } 700^{\circ} \mathrm{C} \\
\text { Useful for metalworking oils }\end{array}$ & $\begin{array}{l}\text { In high vacuum, loses its lubricity } \\
\text { Prone to corrosion at high temperatures (boric acid) } \\
\text { and moist atmosphere } \\
\text { Impurities (e.g. Boron oxide) exert adverse effect on } \\
\text { the } \\
\text { lubrication properties of boron nitride } \\
\text { Medium lubricity that is not retained at high tempera- } \\
\text { ture }\end{array}$ \\
\hline Metal oxides & $\begin{array}{l}\text { Highly lubricity provides fairly low friction at } \\
\text { elevated temperatures } \\
\text { Reduce friction through the formation of "third body" } \\
\text { between the sliding surfaces } \\
\text { Mixed oxides can also provide wider operational } \\
\text { ranges and can be prepared as alloys or composite } \\
\text { structures to provide longer durability } \\
\text { Under a low load, the surface modifier forms adsorp- } \\
\text { tion or chemical reaction film on friction surface } \\
\text { Under a high load, the oxides may form a class of } \\
\text { ceramic films that reduce friction }\end{array}$ & Dispersion stability \\
\hline Organic/polymeric materials & $\begin{array}{l}\text { Bonding strength between the molecules is weak } \\
\text { therefore they can slide past one other at low shear } \\
\text { stresses } \\
\text { Coefficient of friction is lowest of all lubricant addi- } \\
\text { tives } \\
\text { Coefficient of friction does not depend on environ- } \\
\text { ment. It is as low in vacuum as in oxidizing, non- } \\
\text { oxidizing moist and dry atmospheres } \\
\text { Anisotropy in mechanical properties provide good } \\
\text { lubrication properties of the materials }\end{array}$ & $\begin{array}{l}\text { Low melting point } \\
\text { Low thermal conductivity } \\
\text { Relatively low load carrying capacity strength of the } \\
\text { molecules along the length of chains is high }\end{array}$ \\
\hline
\end{tabular}

forces have to be enhanced over the attractive forces. This objective can be achieved by two mechanisms: electrostatic stabilization and steric stabilization.

Various methods have been envisaged to improve the dispersion stability of nano additives in lubricating oils. These include the surface modification using organic compounds, use of surfactants or detergents, in situ preparation of nano additives in base oil, etc. Capping of nanoparticles with organic molecules is a convenient way to stabilize them sterically, which provides a method to generate organic-inorganic core-shell composite with adjustable surface properties. The organic molecules used as capping agent usually have a polar group, which can be chemisorbed on the surface of the inorganic nano-core; and a long alkyl chain, which enables inorganic nanoparticles to dissolve in the organic media [6]. The stability and dispersion of nanoparticles can also be enhanced through electrostatically by regulating the surface potential, hydrophilic layer, and increasing the steric hindrance of the particles, which is achieved through the use of an appropriate 
Table 3 Various nanomaterials used as lubricant additives

\begin{tabular}{|c|c|}
\hline Material class & Nanomaterials \\
\hline metal chalcogenides & $\begin{array}{l}\text { Molybdenum disulfide, tungsten disulfide, tungsten diselenide, niobium selenide, molybdenum diselenide, } \\
\text { tantalum sulfide, copper sulfide }\end{array}$ \\
\hline Metals & $\begin{array}{l}\text { Copper, magnesium, zinc, nickel, chromium, gold, silver, cobalt, aluminum, iron, tin, iron-copper alloy, iron- } \\
\text { cobalt alloy }\end{array}$ \\
\hline Carbon-based materials & $\begin{array}{l}\text { Diamond, carbon nanotube, graphite, fullerene, graphene, carbon nanofiber, graphene oxide, carbon nano } \\
\text { onion }\end{array}$ \\
\hline Metal oxides & $\begin{array}{l}\text { Silica, titania, alumina, iron oxide, copper oxide, cerium oxide, zirconia, zinc oxide, magnesium oxide, molyb- } \\
\text { denum oxide, yttrium oxide, tin oxide, vanadium pentoxide }\end{array}$ \\
\hline Boron-based materials & Boron nitride, boric acid, boron carbide, potassium borate \\
\hline Organic/polymeric materials & Polytetrafluoroethylene, guanidine carbonate, polymethyl methacylate, polyethylene \\
\hline Other materials & $\begin{array}{l}\text { fluoride, silicon nitride, calcium borate, serpentine, lanthanum borate, titanium carbide, zinc borate, lantha- } \\
\text { num borate, magnesium }\end{array}$ \\
\hline
\end{tabular}

surfactant. Various methods used for the stabilization of nano dispersion, their advantages and dis-advantages are described below:

1. Surface modification method

Materials used Oleic acid, stearic acid, ascorbic acid, polyethylene glycol, alkanethiols, octadecyl amine oleyl amine, lauric acid, alkenyl succinimide, amines, silane coupling agents, etc.

- Advantages

(a) Does not considerably affect the physicochemical properties and thus ensues no near loss of the desirable properties

- Disadvantages

(a) Slight increase in the viscosity of the oil on dispersion with surface modified nanoparticles and the viscosity index lies in the upper threshold.

(b) Process up-scaling is a challenge.

(c) Not cost effective

2. Surfactant assisted dispersion

Materials used Conventional surfactants such as sorbital monooleate (SPAN 80), Tween20, CTAB, SDS, etc.

- Advantages

(a) Easy and economical method

(b) No surface pre-treatment required

(c) Well established Method

(d) Availability of wide range of surfactants

- Disadvantages (a) May produce foams when heating

(b) May increase the thermal resistance between the nanoparticles and the base fluid and may limit the enhancement of the effective thermal conductivity

(c) Markedly affect the surface characteristics of a system in small quantity

(d) At higher temperatures the bonding between surfactant and nanoparticles may be damaged resulting in sedimentation of nanoparticles In situ preparation in base oil Good Load carrying capacity

(e) Limited to simple shapes

(f) Complex process and equipment required

Even though surface modified nanomaterials provide better dispersion stability, the process is chemical intensive and hence not much cost effective. On the other hand, dispersion of nanomaterials using conventional surfactants is well-standardized, easy and economical method. This could be reason why conventional surfactants were adopted to achieve the dispersion stability.

\subsubsection{Factors affecting stability of nanomaterials dispersion}

1. For electrostatically stabilized nano dispersions, zeta potential above $30 \mathrm{mV}$ (absolute value) is considered to provide good stability.

2. Selection of surfactant depending on the base fluid is important to achieve optimum stability. For polar base fluids, water-soluble surfactants are preferred while for non-polar medium, oil soluble surfactants are more suitable. While using non-ionic surfactants, those with low HLB values (hydrophilic-lipophilic balance values) are ideal for oil base fluids. 
3. In the case of surface functionalized nanomaterials, the surface coverage of functional groups and compatibility of surface functional groups with the bulk medium affect the stability of dispersion.

\section{Application areas of nanomaterials}

Different types and grades of lubricating oils are used in the industry depending upon the working conditions, operation, and requirement of the machinery itself. Maximum lubricant additives were prepared for automotive oil $(23.08 \%)$, followed by industrial oils $(15.04 \%)$, grease (14.02\%) and metal working oils (4.96\%) [13, 18, 26, 30, 31]. However, $32.48 \%$ of work was done for nano lubricant additives without specifying any lubricant formulation [3].

The consumption volumes of automotive and industrial oils are the highest among various types of lubricant formulations and hence it is apparent that higher number of work has been done in this area. The key advantages of using nano additives in various types of engine oils and industrial lubricants are listed in Table 4.

\section{Technical challenges}

- The major technical hurdle in developing nano lubricant additives is their stability in base oil. The strong van der Waals interactions between nanoparticles always favor the formation of aggregates and eventually results in their sedimentation from the bulk medium [33]. Various methods such as surface modi- fication, surfactant-assisted dispersion and in situ synthesis in base oil have been adopted to realize stable dispersion in the base oil medium. As discussed in the earlier, each of these methods has their own advantages and disadvantages.

- Current trend in nano lubricant development is directed towards formulating stand-alone additive packages, which are nano additive concentrates prepared in base oil. However, the real challenge is to develop fully formulated nano lubricant compositions that contain various other conventional additives along with nano additives [12]. In a fully formulated lubricant, the interaction of nano additive with other conventional additives would play a significant role in stabilizing the nano additive. It has also been observed that the presence of some lubricity enhancers can further de-stabilize the colloidal suspensions. Moreover, the interaction of nano additive should not detrimentally affect the performance of other additives [9]. Thus, development of nano-lubricant formulations balanced in terms of performance and stability is the key technical challenge.

- A changing automotive and industrial landscape is creating demand for higher quality and better performing lubricants and additives. Nano-based lubes could be a game changer in the petroleum industry. The key drivers of nano-lubricant additives are the development of high-performance motor oils, gear oils, compressor oils, heavy duty motor oils, need of better fuel economy, use of ultra-low sulphur diesel, emissions control, increasing the life of the engine oil as well as compatibility of

Table 4 Advantages of Nano Additives in Various Lubricant Compositions

\begin{tabular}{ll}
\hline Lubricant type & Advantages of nano additives \\
\hline $\begin{array}{c}\text { Engine oil (automotive, } \\
\text { marine, railroad, etc.) }\end{array}$ & Continuous surface coating with uninterruptable lubrication layer \\
& Enhance the capacity of oil lubricant to reduce the friction, wear and heat \\
& Enhance extreme pressure properties \\
& Breakdown of $\mathrm{SO}_{x} / \mathrm{NO}_{x}$ in internal combustion engines \\
& Non-corrosive \\
& Reduce engine noise and temperature \\
& A low concentration of nanoparticles is sufficient to improve tribological properties as compared to conventional \\
& additives \\
& Provide high loading capacity and less friction and wear for cutting fluids \\
& Enhance convective heat transfer coefficient of cutting fluids thereby providing improved cooling \\
& Reduce cutting force, work piece surface roughness, tool wear, and chip thickness \\
Improve abrasion resistance, extreme pressure endurance, and heat conductivity of compressor oil \\
Improves the sealing performance, reduces the leakage of refrigerant and improves the volumetric efficiency of \\
compressor oil \\
Improve the extreme pressure properties, friction, wear, and lubricating properties of gear oils \\
Functions as viscosity modifier and thermal conductivity improver for gear oil \\
Provide superior lubricity and torque tension controlling properties, which may result in more uniform clamping \\
loads for anti-seize/lubricating compositions \\
Certain nano additives such as copper provide self-repairing property for grease
\end{tabular}


nano-additives with lubricating oils and other additives [34].

\subsection{Market analysis}

Nano-lube additives industry is a global enterprise with niche markets. Development of nano-lube additives is closely linked to the specific applications and technology. On an average, lubricating oils consist of about $93 \%$ base oils and $7 \%$ chemical additives including nanomaterials (between 0.2 and 40\%). Nanomaterials are used as additives in lubricating oils in a wide variety of vehicle fuel systems as well as industrial applications, including engine oils, compressor oils, gear oils, transmission fluids, coolants, hydraulic oils, greases, and turbine oils and in any other application where metal-to-metal contact moving parts are involved $[35,36]$. The nano-lube additives market is an international marketplace, with customers ranging from petroleum refineries to Original Equipment Manufacturers (OEMs) and automobile workshops and retailers as well. It is highly formulated chemical products (aftermarket) that improve the fuel economy, performance, emission controls, durability and functionality of mineral oils, synthetic oils, and biodegradable fluids. It provides a layer of protection between moving mechanical parts [37]. As the global economy emerges from the great recession of 2010-2011, the nano-lube additives industry finds itself passing through a period of transformation (lab to markets).

In the automotive industry nano-lube additives are largely associated with gasoline and diesel fuels for fuel and power saving, curbing emissions, enhanced physicochemical properties and environmental protection [38]. Nano-additive is selected for its ability to perform one or more specific functions in combination with other (often more than ten) additives. Government regulations have a major impact on nano-lubes business, fuel economy and meeting increasingly stringent emission-control requirements [11]. In highly industrialized countries such as Germany and USA as also in China and India, the total annual cost of friction-and wear-related energy and material losses is estimated to be around $4-10 \%$ of their respective GPD (gross domestic product). Enhanced wear and tear not only reduce the life span of the machine, but also shortens its general maintenance period resulting in more frequent change of oil. Increased friction generates additional heat in the engine leading to overheating and implies increased energy consumption as well as additional cooling, which means increased costs [39]. In recent years, nanomaterials have emerged as a new class of lubricant additives because of their improved tribological performance due to their characteristic structures and properties [40]. Nano-enabled lubricants are effective in decreasing wear and friction in a wide range of industrial and transportation applications. They can also repair wear surfaces to some extent, and thus provide a new way to solve a problem which has remained unsolved for a long time in the lubrication field [41].

\subsection{Key drivers}

A changing automotive and industrial landscape is creating demand for higher quality and better performing lubricants and additives. Nano-based lubes could be a game changer in the downstream petroleum industry, if they could achieve better fuel economy triangle (reduction in boundary friction, low viscosity and in-service retention) as compared to the conventional lubes. Nano-lubes are on-an-average $10 \%$ more expensive than conventional lubes so that in cost analysis, users must not only consider the initial acquisition cost of the lubricant, but also the life cycle cost [42]. The key drivers of nano-lubricant additives are the development of high-performance motor oils, gear oils, compressor oils, heavy duty motor oils, need of better fuel economy, use of ultra-low sulfur diesel, emissions control, increasing the life of the engine oil as well as compatibility of nano-additives with lubricating oils and other additives. Key drivers for the global nano-lubes additives market are depicted in Fig. 4.

\subsection{Commercialization challenges}

It is clear from the studies that certain "conventional" additives are in fact based on nanotechnology. In the past they were designated as colloidal additives. For example, overbased sulfonates, salicylates, phenates are all within the range of nano-dimensions with respect to their solid core $\left(\mathrm{CaCO}_{3}\right)$ [37]. All additive package producers who make overbased detergent additives do use nanotechnology

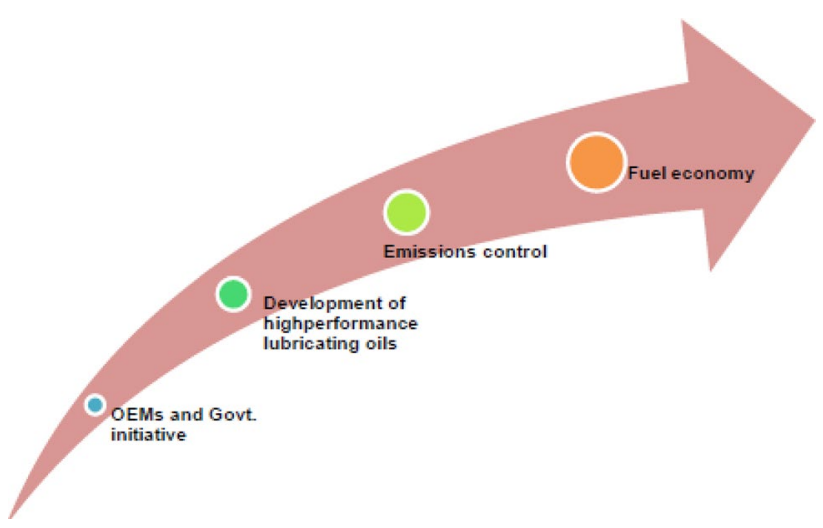

Fig. 4 Key drivers for the global nano-lubes additives 
Fig. 5 Commercialization challenges

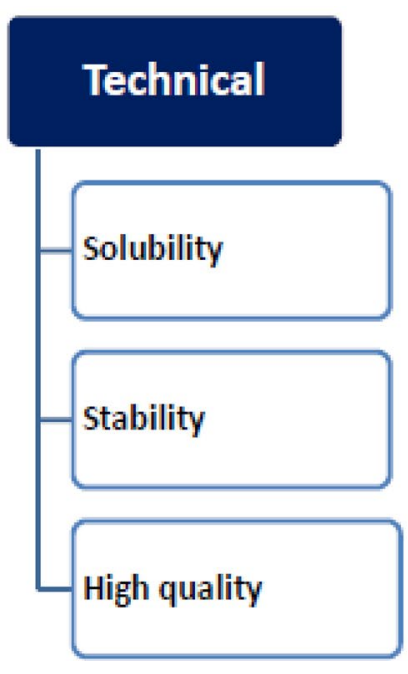

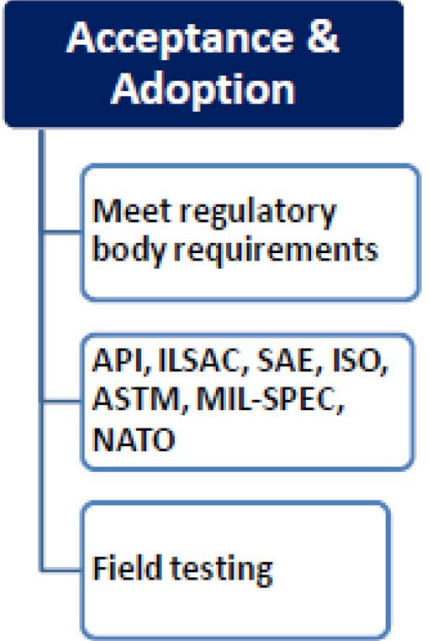

[43-46]. Nano-lubes formulators/blenders are facing following techno-commercial challenges (Fig. 5):

1. Preparation of homogeneous suspension.

2. Viability of adding nanoparticles to formulated oils, which already contain more than 10 additives and the environmental effects of burning nanoparticles containing sulfur etc.

3. Retention of long pot life and higher stability.

4. Lubricant industry is very conservative and not willing to move quickly to evaluate new technologies.

5. Niche nano additive technologies are competing with commodity products.

6. Low initial demand as well as higher cost of production and limited production volume.

7. Higher raw material costs of nano-based lubricant additives as compared to petroleum-based additives.

8. Current extreme pressure (EP) and anti-wear (AW) additives cost less than nano-based lubricant additives.

9. Stringent specifications by regulatory bodies such as API, ILSAC, SAE, ISO, ASTM and NATO.

10. The recommended blends and formulations meeting various API performance levels have been built on non-nanotech. Any change in the blends/formulations will necessarily require additional testing (rig/ bench tests) which will increase the commercialization time and cost.

\subsection{Global nano-lubricants additives market}

Globally, nano-lube additives market is at an early stage, however, is attracting a lot of attention with an increasing number of oil marketing companies making a foray into aftermarket nano-lubes business. The industry is becoming more attractive and is expected to grow faster.
The industrial nano-lubes find industrial applications such as hydraulic fluids, industrial gear fluids, grease, and other specialty applications and in metalworking [42]. The demand for nano-lube additives is mainly driven by growth in vehicle production and the consumption of automotive and industrial lubricants. Majority of automotive nano-lubes demand is derived from commercial vehicles, passenger vehicles and tractors, largely dominated by diesel engines. Gear and hydraulic oils are the biggest demand contributors within industrial lubes [47-50].

\section{Summary}

- The significant technical challenge of achieving stability of nano lubricant additives in base oil has been accomplished using various approaches such as surface modification, surfactant assisted dispersion and in situ synthesis in base oil, which has provided much needed momentum for realizing the commercial potential of these materials.

- The application of nanomaterials is based on carbon, metals, metal oxides, metal sulfides, metal borates, and metal carbonates, in improving the properties and performance of lubricants. The action mechanism of nanoparticles can be stated as: rolling effect, protective film, mending effect, polishing effect, and their tribological properties are affected by particle size, composition, shape, crystallinity, concentration, as well as dispersion stability in base fluids.

- The remarkable tribological properties of nanoparticles, such as their good self-repair function to the worn surface and good environment-friendly property make them excellent candidates for traditional lubricant additives, especially under severe frictional conditions, 
such as high temperature, high load and high sliding speed.

- Nanoparticles were used for enhancing the lubricity of engine oils via boundary lubrication, when the boundary films fail or get broken, solid nano additives can improve the tribological properties by sliding contact surfaces, carry the load and act as back-up lubricating films. Hence, for improved tribology an optimum concentration of nanoparticles is required.

- Nanomaterials have also been explored for various types of lubricants including automotive oils, industrial oils, grease and metal working oils. Among various nanomaterials, most promising ones are copper, nano diamond, carbon nanotubes, silica nanomaterials, molybdenum disulfide, tungsten disulfide, and boron nitride. Except for silica, all other nano-materials have been successfully commercialized as standalone additive package for various lubricant types.

- Addition of nanomaterials as solid lubricant additives can further reduce the content of conventional antiwear, anti-friction or extreme pressure additives in lubricating oils. This would also help to achieve better compliance with the environmental mandates.

- Nano-based lubes could be a game changer in the downstream petroleum industry, if they could achieve better fuel economy triangle (reduction in boundary friction, low viscosity and in-service retention) as compared to the conventional lubes. Nano-lubes are on-anaverage.

- $10 \%$ more expensive than conventional lubes so that in cost analysis, users must not only consider the initial acquisition cost of the lubricant, but also the life cycle cost.

\section{Compliance with ethical standards}

Conflict of interest The authors declare that there is no conflict of interest.

\section{References}

1. Saidur R, Lai YK (2010) Parasitic energy savings in engines using nanolubricants. Energy Educ Sci Technol Part A Energy Sci Res 26(1):6174

2. Socoliuc A, Gnecco E, Maier S, Pfeiffer O, Baratoff A, Bennewitz $R$, Meyer $E$ (2006) Atomic scale control of friction by actuation of nanometersized contacts. Science 313(5784):207210

3. Wu YY, Tsui WC, Liu TC (2007) Experimental analysis of tribological properties of lubricating oils with nanoparticle additives. Wear 262(7-8):819825
4. Li X, Cao Z, Zhang Z, Dang H (2006) Surface modification in situ of nano $\mathrm{SiO}_{2}$ and its structure and tribological properties. Appl Surf Sci 252(22):7856-7861

5. Battez AH, Gonzalez R, Viesca JL, Fernandez JE, Fernandez JMD, Machado A, Chou R, Riba J (2008) CuO, $\mathrm{ZrO}_{2}$ and $\mathrm{ZnO}$ nanoparticles as antiwear additive in oil lubricants. Wear 265(3-4):422-428

6. Lin J, Wang L, Chen G (2011) Modification of graphene platelets and their tribological properties as a lubricant additive. Tribol Lett 41(1):209-215

7. Joly Pottuz L, Dassenoy F, Belin M, Vacher B, Martin JM, Fleischer N (2005) Ultralow friction and wear properties of IF-WS under boundary lubrication. Tribol Lett 18(4):477-485

8. Neville A, Morina A, Haque T, Voong Q (2007) Compatibility between tribological surfaces and lubricant additives how friction and wear reduction can be controlled by surface/lube synergies. Tribol Int 40(10-12):1680-1695

9. Huang HD, Tu JP, Gan LP, Li CZ (2006) An investigation on tribological properties of graphite nanosheets as oil additive. Wear 261(2):140-144

10. Chen CS, Xu XH, Chen LS, Yang Z, Li WH (2005) Modification of multi walled carbon nanotubes with fatty acid and their tribological properties as lubricant additive. Carbon 43(8):1660-1666

11. (2017) The tribological behaviour of nanoparticles mixed lubricating oil-review. Int Res J Eng Technol (IRJET) 4:3217-3228

12. Uflyand IE, Zhinzhilo VA, Burlakova VE (2019) Metal-containing nanomaterials as lubricant additives: state-of-the-art and future development. Friction 7:93-116

13. Lubricant additive and lubricant oil compositions and process of preparing thereof, WO2014033634A2. Indian Oil Corporation Limited

14. Jao T-C, Allen G, Devlin MT, Aradi AA, Allen G, Nanoparticle additives and lubricant formulations containing the nanoparticle additives, US20080161213A1. Afton Chemical Corp, July 3, 2008

15. Titanium and molybdenum compounds and complexes as additives in lubricants, US9249372B2. Lubrizol Corp, Feb 2, 2016

16. Friction modifier composition for lubricants us 20170152459A1, chemtura corporation (middlebury, ct, us)

17. Bardasz EA, Mentor, Method of operating an engine using an ashless consumable lubricant, US20110297122A1. Lubrizol Corp, Jan 27, 2015

18. Adams JH, Rafael S, Calif, Lubricant containing potassium borate, US3997454A. Chevron Research and Technology Co, Dec 14, 1976

19. Burns, Austin JM, Corrosion-inhibited antifreeze/coolant composition containing cyclohexane acid, EP0479471b1. Texaco Development Corp, Feb 28, 1996

20. Lam WY, Guinther GH, Esche CK Jr, Titanium-containing lubricating oil composition, US7776800B2. Afton Chemical Corp, Aug 17, 2010

21. Brown JR, Adams PE, Carrick VA, Dohner BR, Abraham WD, Vilardo JS, Lange RM, Mosier PE, Titanium compounds and complexes as additives in lubricants, US8268759B2, Lubrizol Corp, Sept 18, 2012

22. Preparation of stable carbon nanotube dispersions in liquids, WO2003050332a1 Ashland Inc, June 19, 2003

23. Enhancing thermal conductivity of fluids with graphite nanoparticles and carbon nanotube, WO2003106600a1. Ashland Inc Dec 24, 2003

24. Egami M, Kuwana (JP); Sato Y, Kuwana (JP); Okuda T, Kuwana (JP), Resin composition for sliding member and rolling bearing, US8449200B2. NTN Corp, May 28, 2013

25. Baran JR Jr, Sykora H, Shinbach MP, Boehmer RA, Wuerch DW, Lubricant composition and method of forming, US9284508B2. 3M Innovative Properties Co, Mar 15, 2016 
26. Culpon DH Jr, Port Neches tex, High temperature compressor oil, US5156759A. Texaco Inc, Oct 20, 1992

27. Zhang Z, Smith TR, Wu G, Lockwood FE, Baumgart RJ, Dituro MA, Lubricant and additive formulation, US20050124504A1. Ashland Inc, June 9, 2005

28. Gear oil composition containing nanomaterial, CN101248165A, CN101248165A

29. Zhang Z, Wu G, Lockwood FE, Dotson DJ, Shock absorber fluid composition containing nanostructures, US7470650B2. Ashland Inc Dec 30, 2008

30. Blanski RL, Phillips SH, Rodgers SL, Lichtenhan JD, Schwab JJ (2007) Lubrication via nanoscopic polyhedral oligomeric silsesquioxanes, US7217683B1, Blanski Rusty L, May 15, 2007

31. Branson BT, Irving, Lukehart CM, Nashville, Davidson JM, Brentwood, Materials comprising deaggregated diamond nanoparticles, US8703665B2. Branson Blake T, Apr 22, 2014

32. Migdal CA, Stott PE, Bakunin VN, Parenago OP, Kuz'mina GN, Vedeneeva LM, Suslov AY, Nanosized particles of molybdenum sulfide and method for their preparation, EP1287008B1. Chemtura Corp, June 27, 2012

33. Shindo T, Solid lubricating composition and lubricant agent composition using the same, JP2013144758A. Contamination Control Service KK

34. McLaughlin MJ, Mathur N, Nanoparticle additives and lubricant formulations containing the nanoparticle additives. Afton Chemical Corp, US8333945B2, Dec 18, 2012

35. Haque T, Webster M, Tsou AH, Improved anti-wear performance of lubricants using carbon nanoplatelets, WO2014025523A1. Exxon Mobil Res \& Eng Co, Feb 13, 2014

36. Habeeb JJ, Bogovic CN (2013) Reduced friction lubricating oils containing functionalized carbon nanomaterials, US8435931B2. Exxon Mobil Res \& Eng Co, May 7, 2013

37. Holmberg K, Reponen PK, Harkisaari P, Valtonen K, Erdemir A (2017) Global energy consumption due to friction and wear in the mining industry. Tribol Int 115:116-139

38. Gulzar M, Masjuki HH, Kalam MA, Varman M, Zulkifli NWM, Mufti RA, Zahid R (2016) Tribological performance of nanoparticles as lubricating oil additives. J Nanopart Res 18(8):223

39. Erdemir A (2013) Large-scale manufacturing of nanoparticulatebased lubrication additives for improved energy efficiency and reduced emissions. Argonne National Lab. (ANL), Argonne

40. Saxena ND, Chauhan NR (2019) Nanomaterial in lubricantsa real approach. In: Advances in interdisciplinary engineering.
Part of the lecture notes in mechanical engineering book series (LNME), pp 847-854

41. Niste VB, Ratoi M (2016) Tungsten dichalcogenide lubricant nano additives for demanding applications. Mater Today Commun 8:1-11

42. Wong KV, De Leon O (2010) Applications of nanofluids: current and future. Adv Mech Eng 2:519659

43. Nakagawa A, Mabuchi $Y$ (2013) Lubricant composition, US8598098B2. Nissan Motor Co Ltd, Dec 3, 2013

44. Derevjanik T, Scinto PT, Galic-Raguz M, Titanium compounds and complexes as additives in lubricants, EP2195403B1 Lubrizol Corp, Sept 23, 2008

45. Tsou AH, Minak-Bernero V, Webster MN, Hadjichristidis N, Lubricant compositions and processes for preparing same, US8703666B2. Exxon Mobil Res \& Eng Co, Apr 22, 2014

46. Mosleh M, Hybrid nanolubricant, EP2714874A1. Howard University, May 27, 2011

47. Haishung A, Minak-Bernero T, Webster MN, Hadjichristidis $N$, Lubricant compositions and processes for preparing same, US8703666B2. ExxonMobil Research and Engineering Co, Apr 22, 2014

48. Baran Jr, Sykora H, Shinbach MP, Boehmer RA, Wuerch DW, Lubricant composition and method of forming, US20140100145A1. $3 \mathrm{M}$ Innovative Properties Co., Apr 10, 2014

49. Lockwood FE, Zhang Z, Wu G, Smith TR, Gear oil composition containing nanomaterial, US7449432B2. Ashland Inc, Nov 11, 2008

50. Haque T, Tsou AH, Luo S, Webster MN, Enhanced durability performance of lubricants using functionalized metal phosphate nanoplatelets, US20140011719A1. Exxon Mobil Res \& Eng Co, Jan 9, 2014

Publisher's Note Springer Nature remains neutral with regard to jurisdictional claims in published maps and institutional affiliations. 